\title{
Protagonismo social: encontros entre graduandas de enfermagem de Salvador e ativistas vivendo com HIV
}

RESUMO | Objetivo: Este trabalho objetiva relatar a experiência de graduandas de enfermagem durante encontros com pessoas que vivem com o HIV e participam de um movimento social organizado. Método: A ideia de integrar os encontros promovidos pelo grupo surgiu da necessidade de se aproximar de pessoas que atuam no cenário baiano propondo discussões sobre prevenção, diagnóstico e enfrentamento da epidemia do HIV, objetos do projeto de extensão Bonde Universitário: participação jovem na prevenção de Infecções Sexualmente Transmissíveis, do qual as estudantes fazem parte. Resultado: Os encontros desencadearam rodas de conversas mensais com temas sugeridos pelos participantes: preconceito, perspectiva de futuro e liderança. A ação promoveu a integração entre os participantes e conferiu às graduandas uma prática rica de atenção à saúde. Conclusão: A participação proporcionou a organização de atividades educativas e um aprendizado mútuo, com elaboração de ações inovadoras que tenham potencial para produzir efeitos sobre as práticas sexuais dos sujeitos.

Palavras-chaves: Educação em saúde; Doenças Sexualmente Transmissíveis; Enfermagem.

ABSTRACT | Objective: This work aims to report the experience of undergraduate nursing students during meetings with people living with HIV and participating in an organized social movement. Method: The idea of integrating the meetings promoted by the group arose from the need to approach people who work in the Bahian scenario, proposing discussions about prevention, diagnosis and coping with the HIV epidemic, objects of the Bonde Universitário extension project: young participation in the prevention of Sexually Transmitted Infections, of which the students are a part. Result: The meetings triggered rounds of monthly conversations with themes suggested by the participants: prejudice, perspective of the future and leadership. The action promoted the integration among the participants and gave the undergraduate students a rich practice of health care. Conclusion: Participation provided the organization of educational activities and mutual learning, with the development of innovative actions that have the potential to produce effects on the sexual practices of the subjects.

Keywords: Health education; Sexually Transmitted Diseases; Nursing.

RESUMEN | Objetivo: Este trabajo tiene como objetivo reportar la experiencia de estudiantes de enfermería durante encuentros con personas que viven con el VIH y que participan en un movimiento social organizado. Método: La idea de integrar los encuentros promovidos por el grupo surgió de la necesidad de acercarse a las personas que trabajan en el escenario bahiano, proponiendo discusiones sobre prevención, diagnóstico y afrontamiento de la epidemia de $\mathrm{VIH}$, objetos del proyecto de extensión Bonde Universitário: jóvenes participación en la prevención de Infecciones de Transmisión Sexual, de la cual los estudiantes son parte. Resultado: Los encuentros desencadenaron rondas de conversaciones mensuales con temas propuestos por los participantes: prejuicio, perspectiva de futuro y liderazgo. La acción promovió la integración entre los participantes y brindó a los estudiantes de pregrado una rica práctica del cuidado de la salud. Conclusión: La participación proporcionó la organización de actividades educativas y de aprendizaje mutuo, con el desarrollo de acciones innovadoras que tienen el potencial de producir efectos en las prácticas sexuales de los sujetos.

Palabras claves: Educación en Salud; Enfermedades de Transmisión Sexual; Enfermería.

Lilian Conceição Guimarães de Almeida

Professora Dra. em Enfermagem da Universidade Federal da Bahia.

ORCID: 0000-0001-6940-9187

\section{Rebeca N. dos Santos Mascarenhas}

Graduanda em Enfermagem da Universidade Federal da Bahia.

ORCID: 0000-0001-6155-0290

\section{Jamile Mendes da Silva Santos}

Graduanda em Enfermagem da Universidade Federal da Bahia.

ORCID: 0000-0002-4439-4940

Recebido em: 14/12/2021

Aprovado em: 28/04/2021

\section{Bruna Prates Lopes Brasil}

Graduanda em Enfermagem da Universidade Federal da Bahia.

ORCID: 0000-0002-5246-9519

\section{Jéssica Damasceno de Santana}

Mestre em Enfermagem da Universidade Federal da Bahia.

ORCID: 0000-0002-9018-2391

\section{INTRODUÇÃOO}

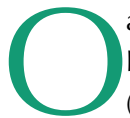
aparecimento do Vírus da Imunodeficiência Humana (HIV) foi vivenciado, inicialmente na década de 80 , com grande sofrimento, visto o processo de adoecimen- to e discriminação sofridos pelas pessoas acometidas. A infecção pelo vírus ocorre, geralmente, por via sexual, com a troca de fluidos ao não usar preservativo vaginal ou peniano, além da transmissão vertical e contaminação com objetos perfuro-cortantes como compartilhamento de seringas.

Atualmente, esta epidemia atinge pessoas de diversas identidades de gênero, raça/cor. classes sociais e gerações que antes não eram consideradas como suscetíveis a esta infecção. ${ }^{1}$

Diante disso, foram muitas as estratégias implementadas para o enfrentamento da infecção pelo HIV/Aids e dentre estas, cabe salientar, o envolvimento da popula- 
ção exigindo acesso à informação, criação de políticas públicas e a inclusão do Sistema Único de Saúde (SUS) como serviço de excelência para atendimento das demandas referentes à epidemia. ${ }^{2} \mathrm{O}$ Programa Conjunto das Nações Unidas sobre HIV/ AIDS (UNAIDS) identificou que o número de novas infecções por Vírus da Imunodeficiência Humana (HIV) caiu 47\% desde o pico em 1996 no Brasil. $^{3}$

Entretanto, apesar dos avanços, as pessoas que vivem com HIV/Aids enfrentam muitas vezes sistemas excludentes, deixando-os em condição de vulnerabilidade. Para Ayres e seus colaboradores, a vulnerabilidade se dá a uma minoria que por motivação individual, social e programática, acarreta maior susceptibilidade de adoecimento devido às diferentes oportunidades de acesso à informação e serviços disponíveis. ${ }^{4}$ Diante dessa afirmação, entende-se que as necessidades de saúde de algumas populações, muitas vezes, não são ouvidas nem levadas em consideração em detrimento dos estigmas que permeiam esse grupo.

Desta forma, surgem movimentos sociais, coletivos de caráter sociopolítico e cultural, que somam forças para transformação dessa realidade, com o objetivo de organização, inclusão, empoderamento e expressão de demandas. ${ }^{5} \mathrm{~A}$ partir da ineficiência do governo na criação de estratégias para o enfrentamento da Aids, as Organizações Sociais surgem e auxiliam no fortalecimento das políticas públicas e lutas pelo direito à melhoria da qualidade de vida. ${ }^{6}$

A partir disso, reconhecendo a importância do tema, foi traçada a seguinte questão de pesquisa: Qual a experiência de graduandas de enfermagem nos encontros com pessoas que vivem com HIV e participam de movimento social organizado?

À vista disto, o presente trabalho objetivou relatar a experiência de graduandas de enfermagem durante encontros com pessoas que vivem com o HIV e participam de movimento social organizado. A ideia de integrar as reuniões promovidas pelo grupo de apoio surgiu da necessidade de aproximação com pessoas que atuam no cenário baiano propondo discussões acerca da prevenção, diagnóstico e enfrentamento da epidemia do HIV, pois estes também são objetos do projeto de extensão Bonde Universitário: participação jovem na prevenção de Infecções Sexualmente Transmissíveis (IST), do qual as estudantes fazem parte.

\section{MÉTODO}

Trata-se de um relato de experiência baseado em atividades desenvolvidas pelo grupo de extensão Bonde Universitário da Escola de Enfermagem da Universidade Federal da Bahia (EEUFBA), vinculado ao projeto de pesquisa Condições de Saúde de Mulheres no Município de Salvador-BA, aprovado pelo Comitê de Ética em Pesquisa, sob o parecer $n^{\circ} 3.919 .332$. Os encontros que originaram esse relato tiveram início em março de 2019 a março de 2020, semanalmente, das 14 às 17 horas, em um serviço de referência situado no município de Salvador-Bahia.

Após a elaboração do projeto de extensão, docentes e discentes estabeleceram uma agenda de discussão e compartilhamento de conhecimento sobre as temáticas prevenção, diagnóstico, tratamento de IST/HIV/Aids, necessidades de saúde e marcadores sociais. ${ }^{7}$ Concomitante a isso, foi estabelecido contato com pessoas do movimento social em busca de informações sobre espaços de discussão e reuniões entre ativistas.

O projeto Bonde Universitário foi apresentado aos ativistas, que demonstraram interesse em uma parceria. As reuniões, a princípio, se davam com poucas intervenções pelos ouvintes, mas foi um espaço importante de vínculo com o Movimento Social e usuários recém-chegados. Em seguida, as reuniões foram abertas ao público e contaram com a participação de estudantes de graduação de Instituições de Ensino Superior (IES), ativistas, profissionais e usuários do serviço. Esta inserção foi favorável para realização de rodas de conversas, organização de ações de prevenção nas ruas, eventos, além da realização de atividades educativas e novas propostas que emergiram ao longo das reuniões.
O serviço onde ocorreram as reuniões realiza atendimentos ambulatoriais para indivíduos com suspeita ou diagnóstico de IST/ HIV/Aids, Assistência Médica, Assistência de Enfermagem, Assistência Social, Nutrição, Odontologia, Terapia Ocupacional, dentre outras especialidades. Este também desenvolve atividades como teatro e dança.

O estudo foi desenvolvido com base nos aspectos éticos da pesquisa, envolvendo seres humanos recomendados pela Resolução 466/2012 do Conselho Nacional de Saúde do Ministério da Saúde, que aborda os deveres e direitos do pesquisador e sujeito. ${ }^{8}$

\section{RESULTADOS}

As reuniões acontecem no serviço de saúde de referência para atendimento de pessoas com HIV. São organizadas pelos ativistas, os quais assumem posturas políticas, usam o espaço como fonte de aprendizado e denúncia sobre os direitos cerceados das pessoas que vivem com o vírus. A maioria dos integrantes vivem com HIV há muitos anos, tinham experiências em múltiplos tratamentos, internações e seus relatos serviam de exemplo para muitas pessoas.

Devido a sensibilização e reconhecimento pelo aprendizado promovido pelas estudantes ao participarem das reuniões, as mesmas propuseram incluir, uma vez ao mês, alguma temática sugerida pelos integrantes ou identificada como pertinente pelo grupo, como pauta. O grupo acolheu a proposta e, a partir disso, foi elaborado cronograma, elencados conteúdos e encontros sob o formato de Rodas de Conversas.

Cada ação era pensada em grupo, todos os aspectos discorridos nas rodas foram realizados a partir da leitura prévia de artigos científicos que possibilitaram atualizações e ampliação dos conhecimentos. Diante do exposto, foram listados três temas centrais para serem trabalhados: preconceito, perspectiva de futuro e liderança.

Sobre o tema preconceito, iniciamos com o desenvolvimento de uma dinâmica para aproximação e integração, na qual os participantes recebiam uma folha em bran$\mathrm{co}$, de um lado foi representada a forma 
como achavam que as pessoas e a sociedade os enxergavam enquanto indivíduos vivendo com o HIV e do outro lado como eles se viam. A atividade possibilitou que fossem promovidas falas em relação a vivência de estigmas de pessoas que vivem com HIV.

Identificou-se que as representações de como os participantes acreditavam ser vistos pela sociedade, em sua maioria, foram simbolizadas por desenhos. Quando provocados a justificá-los, muitos discorreram sobre o preconceito enfrentado no meio familiar durante os anos 90, época de desconhecimento da infecção por parte da sociedade. Além de opiniões diversas sobre revelar ou não a soropositividade. Alguns afirmaram não revelar para família e amigos para proteger-se do estigma, outros achavam melhor comentar nos primeiros contatos como forma de enfrentamento, evitando a violência dessas pessoas.

Em contraponto, a forma como os participantes se viam era majoritariamente representada por palavras que esboçaram sentimentos positivos como o carinho, felicidade e família, sinalizando o quanto eram amados e que o preconceito dos mesmos foi rompido com amor e informação com o passar do tempo. Finalizado esse primeiro momento, os usuários foram convocados para construir uma fala relacionada ao tema.

Um dos ativistas sugeriu a confecção de uma música, uma apresentação com projetos de vida e planos para o futuro. O compositor não compareceu para a roda de conversa sobre perspectiva de futuro, contudo, os demais sujeitos destacaram sonhos, lutas e verbalizaram que viver com HIV deixou de ser uma grande influência para as decisões da vida, pois outros fatores individuais e sociais interferiam mais em suas existências.

Ao final desta segunda roda, todos escreveram em papéis sobre como desejariam estar no futuro e colaram as palavras numa árvore de similitude, confeccionada pelas estudantes, para melhor visualização. A maioria dos participantes considerava como principal para o futuro um envelhecimento saudável e uma morte sem sofrimento. Diante dessas explanações, ressaltou-se que eles poderiam exercer o comando de suas vidas, além de formas de organizar cada passo em direção ao futuro.

Partindo desse pressuposto, foi pensado em conjunto a próxima roda de conversa: a liderança. A abordagem do tema era muito desejada pelas discentes devido o reconhecimento da necessidade de mudança da organização do movimento por conta da sobrecarga de tarefas de alguns integrantes.

Para isso foram utilizadas dinâmicas, os participantes foram subdivididos em grupos e escolheram um representante para comandar a atividade. O líder de cada grupo desta roda mediava a atividade para solucionar o problema proposto. Através disso, percebeu-se diversas formas de integrar, liderar e dividir demandas.

\section{DISCUSSÃO}

Observou-se que havia um canal de comunicação fluido entre o serviço e o movimento, visto que profissionais de diversos setores participavam das reuniões e as dúvidas eram elucidadas sobre as diferentes áreas como a saúde, direito e questões sociais. Mas ocupar aquele espaço é uma luta diária pela permanência, diante cenário de fragilização do SUS, com disputas de ampliação do serviço privado e retirada do auxílio transporte e alimentação que era disponibilizado pelo serviço. No entanto, os ganhos desta articulação foram diversos, as vozes do movimento foram ouvidas pela instituição, assim como estes lutam por melhorias no serviço.

Diversos participantes discorriam nas reuniões sobre o itinerário terapêutico, a trajetória para galgar o que almejavam, orientavam sobre o auxílio-doença, aposentadoria por invalidez ou benefício de prestação continuada. ${ }^{9}$ Além disso, é relevante destacar que a participação do movimento no serviço é importante, pois este desenvolve, junto a unidade, campanhas de informação, prevenção e controle das IST. Essa forma de colaboração com entidades civis sem fins lucrativos é regulada pela Lei n. 9.637/1998. ${ }^{10}$

Observou-se também que a maioria dos participantes tinha idade maior que 40 anos, o que se distingue do perfil epidemiológico da infecção. Estudo realizado entre janeiro de 2012 a maio de 2016, em 112 prontuários de pacientes com diagnóstico de HIV/AIDS, no município de Passos em Minas Gerais, observou a predominância de casos em homens e na faixa etária de 20 a 39 anos. ${ }^{11}$ Essa vivência entre pessoas mais velhas, apesar de importante, pode ser pouco interessante para os jovens, não havendo identificação e estes não se reconhecem como pares. ${ }^{12}$

A ação promoveu a integração e reflexão entre os participantes. Na primeira roda de conversa, muitos relatos esboçaram emoções e sobretudo enfatizaram a importância do papel dos ativistas para extinguir a discriminação impressa as pessoas que vivem com o HIV. Muitos relataram que se sentiam amados por familiares e amigos e que isso os fortaleciam para lutar contra os preconceitos e para construir o futuro. Pois, rodas de conversa podem ampliar as discussões e identificar novos direcionamentos para o grupo. ${ }^{13}$

Esta discussão inicial foi baseada, principalmente, em estudos de Goffman sobre o sujeito estigmatizado, aquele que deixa de ser um indivíduo comum para ser diminuído pela sociedade. ${ }^{14} \mathrm{E}$ para a segunda roda, Robayo e colaboradores a embasou sobre como os integrantes do grupo almejavam estar em 10 anos, sob finalidade de construir ou compartilhar as perspectivas de vida. ${ }^{15}$

Durante a terceira roda, os ativistas foram encorajados a redistribuir funções, compartilhar atribuições e responsabilidades com autonomia para mudança. Percebeu-se que havia um papel importante em despertá-los aos potenciais individuais, a magnitude que as práticas coletivas têm para impactar mudanças. Refletiu-se sobre os espaços e as múltiplas formas de realizar a liderança ética, virtuosa, autêntica e positiva. A prática da liderança carregada de intenção, mas com prudência. ${ }^{16}$

As discussões exibiram o desconhecimento da maioria sobre a liderança exercida em seu dia a dia, acreditavam que ser líder do movimento era uma grande responsabilidade a qual eram incapazes de exercer. Tal percepção resultava na sobrecarga a uma minoria, a partir dos encargos administrati- 
vos a poucos ativistas, estes são vistos como indispensáveis e insubstituíveis para existência e manutenção do movimento.

Notou-se que a interação com o grupo foi positiva e surpreendente. Ao longo das atividades, a troca de experiências evidenciava que o aprendizado era mútuo, a disponibilidade de todos para pensar e elaborar ações coletivas de prevenção das IST unia e os motivava a implementar estratégias inovadoras de abordagem que pudessem produzir efeitos sobre as práticas sexuais dos sujeitos.

A parceria entre a academia e o movimento social organizado conferiu às graduandas uma prática de atenção à saúde real, as aproximou de sujeitos e vivências até então novas. Os relatos sobre a infecção, atendimentos e as relações sociais despertou as graduandas às necessidades subjetivas de cada sujeito envolvido.
CONCLUSÃO

A aproximação entre estudantes de enfermagem, ativistas e usuários do serviço especializado de atenção à saúde de pessoas que vivem com HIV favoreceu a troca de saberes populares e científicos e produziu uma interação entre a universidade e a comunidade. A participação no grupo aproximou as graduandas de sujeitos diversos, dotados de desejos e trajetórias individuais carregadas de aspirações para além da infecção e viabilizou o reconhecimento do ativismo como ferramenta social para a ocupação de espaços e lutas coletivas capazes de mudar não só os cenários existentes, mas as vidas.

Este relato permitiu abordar questões de cunho prático, do campo social e subjetivas que envolvem a emoção. Toda a descrição do ocorrido ao longo das Rodas de Con- versa surge a partir de contextos e histórias de vida, assim a limitação do estudo pode tratar-se de um relato embebido de impressões, percepções individuais, mas que foram compartilhadas pela equipe executora.

A contribuiç̧ão deste artigo está em expor as possibilidades advindas de uma imersão no campo prático que também pode ser teórico. O aprendizado surge do fazer, mas também a partir da reflexão, discussão e descrição minuciosa do que foi feito. A construção do texto fortaleceu o conhecimento adquirido.

Foi possível pensar criticamente sobre os estigmas e compreender as estratégias individuais de defesa cotidiana para sobreviver. Toda experiência propiciou um aprendizado sobre o contexto da saúde, uso de metodologias ativas para promover o acolhimento, a escuta, o cuidado, o vínculo para estabelecer relações entre sujeitos. ?

\section{Referências}

1. Coutinho MFC, O'Dwyer G, Frossard V. Tratamento antirretroviral: adesão e a influência da depressão em usuários com HIV/Aids atendidos na atenção primária. Saúde Debate [internet]. 2018 Jan/Mar [acesso em 2020 jun 17]; 42(116): 148-61. Disponível em: http://revista.saudeemdebate.org.br/sed/article/view/787/59.

2. Melo EA, Maksud I, Agostini R. Cuidado, HIV/Aids e atenção primária no Brasil: desafio para a atenção no Sistema Único de Saúde? Pan American Journal of Public Health [internet]. 2018 [acesso em 2020 fev 27]; 42:e151. Disponível em: https://www.scielosp.org/pdf/rpsp/2018.v42/e151.

3. UNAIDS. "Estatísticas". Brasília-DF; 2017 [acesso em 2019 jun 20]. Disponível em: https://unaids.org.br/estatisticas/.

4. Ayres JR de CM, Calazans GJ, Saletti Filho HC, Franca Junior I. Risco, vulnerabilidade e práticas de prevenção e promoção da saúde. In: Tratado de saúde coletiva. São Paulo: HUCITEC/ FIOCRUZ; 2009.

5. Silva BE. Movimentos sociais: conceitos e suas possibilidades de análises. Rev. Eletrônica do Nemos [internet]. 2019 [acesso em 2020 fev 28]; 4(7): 33361. Disponivel em: http://redelp.net/revistas/index.php/rms/article/view/1silvams06/pdf_33.

6. Tremblay M, Martin DH, McComber AM, McGregor A, Macaulay AC. Understanding community-based participatory research through a social movement framework: a case study of the Kahnawake Schools Diabetes Prevention Project. BMC Public Health [internet]. 2018 [acesso em 2020 mar 17]; 1-17. Disponivel em: https://bmcpublichealth.biomedcentral.com/track/pdf/10.1186/ s12889-018-5412-y.

7. Miranda SVC de, Oliveira PSD, Moraes VC de M, Vasconcellos LCF de. Necessidades e reivindicações de homens trabalhadores rurais frente à atenção primária à saúde. Trab. Educ. Saúde [internet]. 2020 [acesso em 2020 mar 11]. 18(1). Disponivel em: http://www.scielo.br/scielo.php?script=sci_arttext\&pi$\mathrm{d}=\mathrm{S} 1981-77462020000100500 \& \mathrm{lng}=\mathrm{en} \& \mathrm{nrm}=$ iso.

8. Brasil. Ministério da Saúde. Conselho Nacional de Saúde. Resolução n 466 , de 12 de dezembro de 2012. Dispõe sobre diretrizes e normas regulamentadoras de pesquisas envolvendo seres humanos [internet]. Diário Oficial [da] República Federativa do Brasil, Brasília (DF) 13 jun. 2013 [acesso em 2021 mar 24]. Disponível em: https://bvsms.saude.gov.br/bvs/saudelegis/cns/2013/ res0466 $12 \quad 12$ 2012.html.

9. Silva NLT da, Alkimim MA. Hiv/aids e efetivação do direito fundamental à saúde e previdência social: incapacidade de acordo com a súmula 78 da Turma Nacional de Uniformização (TNU). Rev. de Direitos Sociais, Seguridade e Previdência Social [internet]. 2017 July/Dec [acesso em 17 mar 2020]; 3(2): 63-84. Disponível em: https://indexlaw.org/index.php/revistadssps/article/view/2461/pdf.

10. Brasil. Presidência da República. Casa Civil. Subchefia para Assuntos Jurídicos. Lei $n^{\circ} 9637,15$ de maio de 1998. Dispõe sobre a qualificação de entidades como organizações sociais, a criação do Programa Nacional de Publicização, a extinção dos órgãos e entidades que menciona e a absorção de suas atividades por organizações sociais, e dá outras providências [internet]. Diário Oficial [da] República Federativa do Brasil, Brasília (DF); 1998 May [acesso em 2019 jul 18]. Disponivel em: http://www.planalto.gov.br/ccivil_03/leis//9637.html. 11. Moura JP de, Faria MR de. Characterization and epidemiological profile of people living with HIVIAIDS. J Nurs UFPE on line [internet]. 2017 Dez [acesso em 2020 mar 10]; 11(Supl. 12):5214-20. Disponível em: https://periodicos. ufpe.br/revistas/revistaenfermagem/article/view/22815/25536.

12. Calazans GJ, Pinheiro TF, Ayres JR de CM. Vulnerabilidade programática e cuidado público: Panorama das políticas de prevenção do HIV e da Aids voltadas para gays e outros HSH no Brasil. Sex., Salud Soc. (Rio J.) [internet]. 2018 [acesso em 2020 mar 17]; (29): 263-93. Disponível em: http://www.scielo.br/scielo. php? script=sci_arttext\&pid=\$1984-64872018000200263\&lng=en\&nrm=iso. 13. Trindade MP, Monteiro EL." Sabia que a linha da pipa serve pra costurar roupa?": diálogos em roda de conversa com crianças da educação infantil na llha de Mosqueiro, Pará. Cadernos da Pedagogia [internet]. 2019 out/dez [acesso em 2020 mar 1]; 13(26): 46-59. Disponível em: http://www.cadernosdapedagogia.ufscar.br/index.php/cp/article/view/1109/474.

14. Goffman E. Estigma: notas sobre a manipulação da identidade deteriorada. Tradução de Mathias Lambert. 4 ed. Rio de Janeiro: LTC, 1988.

15. Robayo AMM, Narváez MRT, Alvarez EDH, Puche AG, Duarte MLP, Peña MAZ. Características del desempeño ocupacional de un grupo de adultos que viven con VIH-SIDA. Cad. Bras. Ter. Ocup. [internet]. 2017 [acesso em 2020 mar 10]; 25(1): 85-93. Disponível em: http://www.cadernosdeterapiaocupacional. ufscar.br/index.php/cadernos/article/view/1428/818.

16. Guimarães M, Ferreira MC, Pereira M. Evidências iniciais de validade da escala de liderança virtuosa. Estud. Psicol. (Campinas, Online) [internet]. 2019 Jan [acesso em 2020 mar 17]; 36: 1-10. Disponivel em: http://www.scielo.br/scielo. php?script=sci_arttext\&pid=S0103166X2019000100603\&lng=en\&nrm=iso. 